BULLETIN Bulletin hispanique

HISPANIQUE Université Michel de Montaigne Bordeaux

118-2 | 2016

Varia

\title{
Traducción y censura en la España franquista
}

Un caso de recepción de Claudine à Paris de Colette

María J. García-Domínguez, Marina Díaz-Peralta y Gracia Pinero-Pinero

\section{OpenEdition}

Journals

Edición electrónica

URL: http://journals.openedition.org/bulletinhispanique/4586

DOI: 10.4000/bulletinhispanique.4586

ISSN: 1775-3821

Editor

Presses universitaires de Bordeaux

Edición impresa

Fecha de publicación: 15 diciembre 2016

Paginación: 591-610

ISBN: 979-10-300-0125-9

ISSN: 0007-4640

Referencia electrónica

María J. García-Domínguez, Marina Díaz-Peralta y Gracia Pinero-Pinero, «Traducción y censura en la España franquista », Bulletin hispanique [En línea], 118-2 | 2016, Publicado el 15 diciembre 2019, consultado el 28 diciembre 2019. URL : http://journals.openedition.org/bulletinhispanique/4586 ; DOI : 10.4000/bulletinhispanique.4586 


\title{
Traducción y censura en la España franquista. Un caso de recepción de Claudine à Paris de Colette ${ }^{1}$
}

\author{
María J. García-Domínguez, Marina Díaz-Peralta, Gracia Pinero-Pinero \\ Universidad de Las Palmas de Gran Canaria
}

En partant de l'hypothèse selon laquelle le traducteur, fort de son bagage cognitif, interprète le texte qu'il traduit et que la traduction est un phénomène de réécriture, cet article analyse la version espagnole de l'œuvre de la romancière française Sidonie Gabrielle Colette, Claudine à Paris, traduite par Pińas en 1963. L'objectif de cette analyse est de démontrer comment une circonstance historique concrète, la censure imposée par la dictature franquiste, influe sur la traduction.

Mots-clés: censure, dictature franquiste, traduction, manipulation, Colette.

Partiendo de la premisa de que el traductor interpreta el texto que traduce aportando a esta interpretación su bagaje cognitivo y de que, por tanto, la traducción es un fenómeno de reescritura, este trabajo analiza la versión española de la novela Claudine à Paris, de la escritora francesa Sidonie Gabrielle Colette, traducida por Piñas en 1963, con el fin de demostrar cómo una circunstancia histórica concreta, la censura impuesta por la dictadura franquista, incide sobre el trabajo de traducción.

Palabras clave: censura, dictadura franquista, traducción, manipulación, Colette.

Assuming that the translator, cleverer from his stock of cognitive knowledge, interprets the text he translates, and that translation is a phenomenon of rewriting, this article examines the Spanish version of "Claudine à Paris» by the French novelist Sidonie Gabrielle Colette, translated by Piñas in 1963 . The analysis aims at demonstrating how concrete historical circumstances -the censorship imposed by Franco's dictatorshipinfluences the work.

Keywoords: censorship, Franco dictatorship, translation, manipulation, Colette.

1. Las autoras de este trabajo forman parte del grupo de investigación Cognition, Linguistics, Text and Information perteneciente al Instituto Universitario de Análisis y Aplicaciones Textuales (IATEXT) de la Universidad de Las Palmas de Gran Canaria. Este artículo se inscribe en una de sus líneas de trabajo relacionada con la manipulación y la reescritura de los textos traducidos al español. 


\section{INTRODUCCIÓN}

El objetivo de este trabajo es demostrar que las restricciones ideológicas que afectan a Piñas, quien en 1963 traduce al español la obra de Colette Claudine à Paris, repercuten sobre el texto de la novela y, consecuentemente, sobre la interpretación que de ella hace el público español, y que esas restricciones vienen determinadas por la situación política de España en el periodo de la dictadura franquista.

Para lograr nuestro objetivo hemos cotejado esta traducción con otra versión española aparecida en 1910 y firmada por Ruiz Contreras, con el fin de llevar a cabo un análisis comparativo. Pensamos que estas dos traducciones, pertenecientes a dos épocas históricas distintas, representativas, además, de diferentes etapas de la historia de la literatura española del siglo XX, como explicaremos enseguida, permitirán una visión contrastiva de sus especificidades, que vendrán motivadas por el momento histórico en el que se lleva a cabo la traducción.

El cotejo de la traducción de 1963 con la de 1910, y de ambas con el texto original francés, nos ha permitido extraer las variantes que presenta la versión de Piñas y que pueden ser definidas como variantes ideológicas, pues, como trataremos de demostrar, se relacionan con los principios de la censura franquista, formulados por Abellán (1980: 88) en cuatro puntos:

1. Moral sexual. Entendida como prohibición de cualquier expresión que implicara, de alguna manera, un atentado contra el pudor y las buenas costumbres en todo lo relacionado con el comportamiento sexual, lo que impide referencias al aborto, la homosexualidad y el divorcio.

2. Opiniones políticas contrarias a la doctrina oficial.

3. Lenguaje considerado provocativo, indecoroso e impropio de los buenos modales.

4. La religión, como institución y jerarquía, depositaria de todos los valores divinos y humanos.

Intentaremos mostrar cómo el traductor de 1963 aplica estrategias destinadas a atenuar determinados contenidos potencialmente agresivos, desde un punto de vista moral, para la cultura meta. En efecto, como veremos enseguida, Piñas recurre a la supresión o a la modificación de determinados segmentos del texto de la novela que traduce con el fin de adecuarlo a las expectativas de la audiencia receptora, así como para evitar, tanto para él mismo como para la empresa editora, los problemas derivados de la «falta de respeto» a las normas ideológicas vigentes.

Las hipótesis de nuestro trabajo se relacionan con el concepto de censura institucionalizada, esto es, la sujeción a las normas morales imperantes en un momento concreto, la España de 1963, a causa de una circunstancia histórica específica, la dictadura de Franco. Asimismo, estas hipótesis, que se formulan a continuación de acuerdo con los principios de Abellán (1980: 88), tienen en cuenta la naturaleza del texto original, Claudine à Paris: 
1. El traductor de 1963 dedicará especial atención a los aspectos relacionados con la moral sexual y manipulará el texto con el fin de suavizar aquellas situaciones que sobrepasen los límites socialmente aceptados del pudor y las buenas costumbres.

2. El traductor dedicará su esfuerzo a buscar recursos que atemperen los segmentos textuales que presenten un lenguaje que en la sociedad española de la época pudiera ser considerado provocativo o indecoroso.

3. El traductor pondrá especial cuidado en el tratamiento de cualquier aspecto que afecte a la religión y que pueda considerarse ofensivo o irreverente, de acuerdo con los presupuestos morales de la religión católica imperantes.

4. Dado que la obra que se estudia no posee un componente político, el traductor no tendrá que modelar el texto traducido con el fin de evitar opiniones políticas que pudieran ser consideradas contrarias a la doctrina oficial.

\section{EL CORPUS: EL TEXTO ORIGINAL Y LOS TEXTOS TRADUCIDOS}

El corpus de nuestra investigación está constituido por el texto Claudine à Paris, de Sidonie Gabrielle Colette, que sirve de marco a dos traducciones al español de esta obra: la versión de 1963 y la versión de 1910.

Claudine à Paris fue editada por primera vez en París por la Société d'Éditions Littéraires et Artistiques, Librairie Paul Ollendorf, el 23 de febrero de 1901. Para nuestro trabajo hemos utilizado la edición francesa de la colección Bibliothèque de la Pléiade, publicada por las Ediciones Gallimard, el 20 de septiembre de 1989. Este volumen, que figura con el número 314 de la citada colección, contiene, además de la serie Claudine, otras obras de la misma autora, como $\mathrm{La}$ vagabonde, Chéri o L'ingénue libertine.

La primera de nuestras traducciones, obra de Ruiz Contreras, es editada por Francisco Beltrán, Librería Española y Extranjera, en Madrid, en el año 1910. Ruiz Contreras (Castellón 1883 - Madrid 1953), además de traductor, es un escritor que formó parte de la generación de 1898 y destacó como una de sus figuras secundarias más importantes junto a Ciro Bayo y Segurola y al periodista Manuel Bueno, entre otros. Entre sus obras destacan Dramaturgia castellana, Palabras y plumas o La tierra natal. Entre sus traducciones del francés sobresalen las Obras completas de Anatole France y de Guy de Maupassant (Ruiz Casanova 2000: 473).

La segunda de nuestras versiones españolas fue realizada por Pińas y editada en 1963 en Barcelona por la editorial Plaza y Janés. De los títulos traducidos por Piñas, destacamos la obra de Colette Dúo, en 1983, o El Gran Gatsby, de Scott Fitzgerald, en 1999.

Por su cronología, hemos denominado Texto Meta 2 (TM2) a la traducción de 1963, que es nuestro objeto de estudio, y Texto Meta 1 (TM1) a la traducción de 1910, que será el instrumento que nos permitirá aplicar un método comparativo para el análisis. 


\section{Justificación del corpus}

Varios son los motivos por los que consideramos idónea la novela de Colette Claudine à Paris para abordar el concepto de censura en la traducción. En primer lugar, porque se trata de una obra cuya temática, presumiblemente, rompería los cánones morales de la sociedad española, por entonces mucho más conservadora que la francesa.

Por otra parte, hemos constatado que, en los dos primeros tercios del siglo $\mathrm{XX}$, no eran frecuentes las versiones en español de Colette, hecho que, sumado a la relativa escasez de traducciones de novelas francesas en el periodo de postguerra, podría significar que se trataba de una obra alejada de los gustos de la sociedad española.

Hemos seleccionado la traducción de 1963 porque esta fecha es anterior a la entrada en vigor de la Ley de Prensa e Imprenta del ministro Fraga Iribarne (1966) y, por tanto, constituye un momento en el que aún están vigentes los presupuestos de la censura institucionalizada fijados en plena guerra civil. Se trata, además, de una fecha posterior a la publicación, en 1962, de Tiempo de Silencio de Martín Santos, acontecimiento que marca el comienzo de la etapa de apertura de la sociedad espańola a la cultura exterior ${ }^{2}$.

Asimismo, nos parece importante estudiar el fenómeno de la censura en la traducción de un texto literario ${ }^{3}$, en concreto en una novela, porque, al contrario de lo preconizado tradicionalmente en lo que respecta al valor secundario de las traducciones para el acervo literario nacional o autóctono (Gallego Roca 2004: 479), creemos que estos textos pasan a formar parte del polisistema cultural de la lengua meta, en este caso, el espańol, y se integran en él como uno más de sus elementos constitutivos. A este respecto afirma Santoyo (1983: 41): «A pesar de que todo estudio de un polisistema literario debería siempre incluir una parte referente a la literatura traducida que forma parte de él, a menudo esta es obviada y no se le da la importancia que merece. [...] En el caso concreto de la literatura espańola vivimos inmersos en una cultura cuyo rasgo más característico, más señalado y decisivo es el de ser una cultura traducida».

2. Afirma Amorós (1987: 20) que la muerte de Franco no supuso una «conmoción trascendental» y que la verdadera conmoción hay que situarla en 1962, como consecuencia de la publicación de la obra de Martín Santos. Así pues, en el periodo comprendido entre la guerra civil y la muerte del dictador hay que contar con dos etapas: una anterior y otra posterior a dicho año.

3. Hemos estudiado el efecto de la manipulación ideológica en la traducción del texto histórico. Cf. Díaz Peralta, Piñero Piñero y García Domínguez, «Ideología y selección lingüística en los textos históricos: las traducciones españolas de History of the conquest of Mexico de W. H. Prescott», Babel 54:3, 2008, pp. 251-267; y Díaz Peralta, Piñero Piñero y García Domínguez, "Adaptation Strategies in historical texts: The Spanish version of History of the Reign of Philip the Second, King of Spain by William H. Prescott», Intercultural Pragmatics 10:3, 2013, pp. 495-520; Díaz-Peralta, Pinero-Pinero, García-Domínguez y Boylan, «Metaphor and symbol: The portrait of Montezuma II in the work of W. H. Prescott and its translation into Spanish by J. Navarro", Babel 61:2, 2015, pp. 242-264. 
Es más, el régimen franquista, a través de los mecanismos de la censura oficial, ejerce un mecenazgo (Lefevere 1997: 27), que es responsable de la selección de los textos que pueden ser traducidos y publicados, del mismo modo que controla toda manifestación cultural autóctona. Este mecanismo de control recurre a la traducción de obras extranjeras, especialmente en inglés, durante la primera etapa del régimen, debido a la escasez de producción nacional causada por la desaparición de escritores durante la propia guerra o por el exilio de otros muchos. Las obras seleccionadas, porque resultaban adecuadas a los postulados del régimen, eran novelas inglesas victorianas que presentaban una vida familiar, cotidiana, propia de la alta burguesía británica, de autores como Brontë o Thackeray; o bien de entretenimiento como la de aventuras, la de detectives o la novela rosa.

Paradójicamente, la cultura francesa, privilegiada a lo largo de la historia española ${ }^{4}$, queda relegada a un segundo plano en el periodo de posguerra, posiblemente por las malas relaciones políticas entre los dos países (Vega 2004: 545) y por la reputación de inmoralidad que adquiere en España la literatura francesa (Pegenaute 2004: 461-462). La situación cambiará a partir de los ańos 60, cuando autores modernos como Colette, André Maurois o Françoise Sagan invaden las colecciones de bolsillo de Plaza y Janés (Vega 2004: 546).

Un símbolo de este cambio es la publicación de Tiempo de Silencio, de Martín Santos, en 1962, momento que, como acabamos de señalar, se considera el inicio de una nueva trayectoria de la novela y también de la cultura española.

Tales son las circunstancias que justifican la elección de nuestro corpus. Hemos de precisar que este estudio tiene como objetivo el análisis del texto traducido, el que muestra la traducción como resultado y no como proceso, de acuerdo con la concepción de Toury (1985: 23-31), que considera las traducciones dentro de la cultura meta que las acoge, pues será esta la que determine su función. En la misma línea, entendemos la traducción como un acto de comunicación intercultural que va más allá de las fronteras lingüísticas o literarias y que se encuadra en el contexto global de la cultura (Rabadán 1992: 49).

\section{Cultura y traducción. La traductología}

La escuela traductológica Estudios de Traducción y la Teoría del Polisistema de Toury, que culminan en la denominada Escuela de la Manipulación, ponen de relieve la complejidad del trabajo del traductor al considerar que este no lleva a cabo su labor utilizando exclusivamente el texto original como modelo. De

\footnotetext{
4. En este sentido, Cobos Castro reúne casi trescientas novelas populares francesas traducidas y editadas en España entre 1840 y la primera década del siglo XX. Cf. «Narrativa y traducción: la novela popular francesa traducida al español en la 2a mitad del siglo XX», Estudios de investigación franco-española 12, 1995, pp. 185-216.
} 
la concepción del traductor como simple instrumento de transmisión entre un texto y otro texto, que son los verdaderos protagonistas, se pasa a considerar al traductor como un factor esencial de la traducción, con su carga ideológica, su humanidad y sus circunstancias vitales o culturales, que desarrolla su tarea en el seno de la poética cambiante y no inmutable de la cultura receptora.

Esta corriente de la traductología centra su interés en los textos literarios y en el examen de traducciones concretas y pone de relieve, desde la base de su pragmatismo, la importancia del análisis del funcionamiento del texto literario en el sistema cultural receptor (Hermans 1985: 10). A partir de este momento, se pone el interés en la recepción del texto traducido y se valoran las aportaciones que el traductor incorpora a su trabajo a título individual, como consecuencia de los cánones vigentes en el sistema de la cultura meta.

Simultáneamente, el carácter práctico de estas investigaciones, que privilegian el estudio de traducciones concretas, implica una concepción del carácter histórico de los textos traducidos, pues cada traducción será, sobre todo, hija de sus circunstancias históricas. Así pues, si el texto original es inmutable, al menos en lo que se refiere a su materialidad -ya que no a su significado-, el texto traducido sufre adaptaciones derivadas de las modificaciones culturales que introduce el paso del tiempo (Moya 2004: 129).

Por todo ello, un texto original puede tener tantas traducciones como traductores, quienes llevan a cabo su labor mediante un complicado proceso de toma de decisiones mediatizadas por múltiples factores (Holmes 1988: 25). De este modo, se viene a postular que la traducción literaria no deja de ser un fenómeno de metaliteratura, al igual que lo es la crítica literaria, puesto que supone un acto de interpretación del texto por parte del traductor. Este principio está en la base del concepto de traducción como reescritura (Lefevere 1887), con el que se revaloriza el texto traducido y se confiere al traductor el papel de autor o coautor; y a la obra literaria traducida, la consideración de obra literaria en la cultura meta (Holmes 1988: 25, 50 y 58).

A partir de esta teoría comienza a desdibujarse el carácter sagrado del original, y sus desviaciones ya no se verán como traiciones o muestras de la incompetencia del traductor, sino como un condicionamiento del sistema literario meta; se relativiza el concepto de equivalencia y se desecha la idea de la traducción perfecta. Por tanto, empieza a ser necesario contar con la infidelidad del traductor y empieza a hablarse de la manipulación del original. Habrá que tener en cuenta el texto original, la lengua meta, el tiempo en el que se lleva a cabo la traducción, la cultura receptora, la literatura traducida y su función dentro de esa cultura, la ideología, la poética del momento y del propio traductor, el poder que dicta el contenido de las normas o lo que es o no correcto, etc. (Moya 2004: 152-154). En este sentido, Lefevere (1997) introduce definitivamente en el panorama de la traductología el principio de que toda reescritura implica una manipulación y de que los traductores o reescritores manipulan los originales para hacer que se ajusten a la ideología y a la poética de su época. 
Precisamente el factor ideológico posee una intensa fuerza coercitiva sobre el trabajo de los escritores en general y de los traductores en particular. El propio escritor-traductor o algún tipo de agente externo ejercen una vigilancia constante sobre el trabajo de creación para impedir la manifestación de todas aquellas cuestiones que puedan obstaculizar el éxito del trabajo. Estos dos factores se pueden identificar con dos tipos de censura: de una parte, la censura institucionalizada, ejercida por el Estado y por cualquier centro de poder empresarial, y, de otra, la autocensura, que lleva a cabo consigo mismo el propio escritor-traductor con independencia de que exista una censura externa o no.

A este respecto, Beneyto (1975) incluye una pregunta sobre la autocensura en el cuestionario que somete a la consideración de cuarenta y tres escritores con el fin de examinar la incidencia de la censura franquista en la producción literaria española desde la guerra civil hasta la muerte de Franco. Todos ellos reconocen que escriben bajo el peso de la propia conciencia censora. Son interesantes en este sentido declaraciones como la de Miguel Delibes, que traemos aquí como muestra de las de los restantes escritores entrevistados: «No creo que mi ideología haya sufrido grandes alteraciones desde que maduré, desde los 22-25 ańos. Lo que ha sufrido alteraciones ha sido la censura y, de acuerdo con estas alteraciones, yo abro o cierro el grifo" (en Beneyto 1975: 191). Si los propios creadores declaran que están sometidos a las restricciones ideológicas de su entorno, hemos de suponer que estas restricciones afectan con igual o mayor intensidad a los profesionales de la traducción. Como señala Abellán (1980: 67) -y estas afirmaciones son perfectamente extrapolables a la actividad de los traductores-, por regla general el escritor español medio ha preferido ceder ante las exigencias, a veces humillantes, de la censura, «ha negociado, modificado, suprimido, atendido o no los sugestivos consejos de la administración censoria pero, sobre todo, se ha autocensurado, consciente, obvia e incluso instintivamente».

\section{La censura institucionalizada}

En febrero de 1947, Franco declaraba en el diario The Evening Star que «el pueblo espańol goza de unas libertades que son desconocidas en el este y centro de Europa. Hay limitaciones a esta libertad, pero solo aquellas que se necesitan para mantener el orden, pues no debemos olvidar que con el desorden acaban todas las libertades» (Suárez Fernández 1984: 149).

Con estos presupuestos, era evidente la justificación de la censura previa para toda publicación. El régimen de Franco quiso eliminar de los medios de comunicación todo lo que no era conveniente para sus planes.

Esta mentalidad dio lugar a una de las etapas más negras de la historia de la cultura, presidida por un espíritu de revancha que llevó al bando ganador a imponer sus «estrechas y alicortas ideas», según testimonia Laín Entralgo 
(1976: 242), mediante una censura "dogmática, xenófoba y pudibunda», como la define Dionisio Ridruejo (en Beneyto 1975: 124). Así concebida, la censura fue durante años opresora, arbitraria e irresponsable y causó «un grave trauma en el pensamiento de un par de generaciones», según denuncia Rosa Chacel (en Beneyto 1975: 178). Como afirma Sinova (1989: 63), «al régimen no le interesaba tanto convencer como vencer, por ello más que a elaborar teorías o principios se aplicó a ejercer tajantemente una censura que se comportó como un mecanismo de dominio y sumisión».

La norma que consiguió poner toda la información al servicio permanente del Estado fue una ley dictada con carácter provisional el 22 de abril de 1938, un año antes del fin de la guerra civil, firmada por el entonces ministro del Interior, Serrano Súñer.

Esta ley, redactada en plena guerra civil, reúne 23 artículos que ejercen un severo control no solo sobre la prensa, a la que va especialmente dirigida, sino también sobre los demás géneros como los libros, los folletos, las revistas, así como sobre los restantes medios de información y cultura como la radio, el teatro y el cine, los espectáculos en general y cualquier manifestación cultural.

Hasta el año 45 no se admite una excepción a esta norma, cuando se suprime la censura para las publicaciones de carácter litúrgico, los textos latinos usados por la Iglesia Católica, las obras de literatura anteriores a 1800 y las musicales con letras anteriores a 1900 .

Las disposiciones derivadas de la ley de 1938 quedaron vigentes hasta el año 1966, fecha en la que entra en vigor una nueva disposición, la Ley de Prensa e Imprenta, impulsada por el entonces ministro Fraga Iribarne y aprobada por las Cortes el 15 de marzo. Básicamente, la nueva norma suprimía la obligación de la censura previa, pero no implicaba su desaparición, pues esta seguiría presente mediante mecanismos como el del secuestro de publicaciones; y Beneyto (1975: 17) la reconoce todavía vigente en 1975, a escasos meses de la muerte del dictador.

Por otra parte, Abellán (1980: 88) distingue dos tipos de criterios en el ámbito de la censura franquista: los fijos y los variables. Los primeros, de carácter político, hacían referencia al sistema institucional franquista y resistieron el paso del tiempo hasta la muerte de Franco. Los segundos, variables, se relacionaban con la moral pública, eran la copia literal de los principios que constituían el integrismo católico y fueron poco a poco abandonados por las clases medias tradicionales al mismo tiempo que la Iglesia Católica iba perdiendo la posición privilegiada de la que había disfrutado.

\section{ANÁLISIS}

Abordamos el análisis de variantes a partir de las tres líneas maestras que, de acuerdo con nuestras hipótesis, guían la actuación del traductor, líneas que vienen determinadas por tres de los dogmas promovidos por la dictadura franquista, tal y como los formula Abellán (1980: 88). Estos dogmas se 
relacionan básicamente con la moral sexual, el lenguaje provocativo e indecoroso y las actitudes irrespetuosas con los principios de la moral católica. Ha quedado excluido de nuestro trabajo un cuarto principio, el político, porque Claudine à Paris constituye una novela carente de intencionalidad política explícita.

Hemos de precisar que estos tres principios están estrechamente vinculados entre sí, de tal modo que resulta prácticamente imposible diferenciar claramente una variante relacionada con la moral sexual que no esté, a la vez, ligada a la moral católica. Al mismo tiempo, el lenguaje "provocativo e indecoroso" está, igualmente, emparentado con el ámbito de la conciencia religiosa y sexual. Recordemos que en este sentido se llegó a sobrepasar la barrera del ridículo: "Palabras como "axila, ombligo y calzoncillos" eran tachadas porque evocaban en la mente del censor el desdeñable sexo" (Sinova 1989: 247).

Mostraremos cómo Piñas se vale para su trabajo de dos estrategias: la omisión, que le permite soslayar los contenidos «peligrosos» o, al menos, desdibujar su perfil; y la modificación, que responde a una técnica léxico-semántica y sintáctica, destinada, igualmente, a transformar el texto siguiendo los dictados de su intención comunicativa.

Analizamos, a continuación, las variantes presentando, en primer lugar, el texto original (TO), que va seguido de los textos traducidos. Tal y como señalamos en páginas anteriores, el texto traducido 1, en adelante TM1, es el texto de 1910, obra de Ruiz Contreras; y el texto traducido 2, en adelante TM2, es el texto de 1963, de Piñas.

Hemos utilizado la negrita para destacar las variantes que han resultado del cotejo del TM1 y del TM2 y que son el objeto de nuestro análisis. Cuando en el TM2 existe una omisión, la hemos seńalado con el signo Ø. Igualmente, en cada caso se consigna el número de página en el que se encuentra la variante, siempre referido a la correspondiente edición.

\section{Variante 1}

He aquí una cancioncilla que suele cantar el padre de Claudine. En ella es importante el uso de la rima.

TO) Les Anglais pleins d'arrogance/ Sont venus assiéger Lorient/ Et les bas Bretons (on ne peux pas citer le reste, malheureusement) (p. 226).

TM1) Los ingleses, llenos de arrogancia, intentaron conquistar la Francia/sin pensar que tienen los bretones (No me atrevo a escribir la conclusión) (p. 13).

TM2) Los ingleses llenos de arrogancia han sitiado Lorient/y las gentes de la baja Bretańa (desgraciadamente no se puede citar la continuación) (p. 246).

En esta variante, Piñas opta por transformar la secuencia «les bas Bretons» por «las gentes de la baja Bretańa» con la finalidad de evitar la rima de la palabra «Bretón», que en español remite a una expresión malsonante muy frecuente. Esta precaución no se constata en el TM1. 


\section{Variante 2}

Claudine relata a su amigo Marcel cómo había respondido con un gesto obsceno a un señor que la había seguido por las calles de París.

TO) J'ai eu la malencontreuse idée de lui tirer une langue pointue. «Oh, donnez-la-moi», qu'il a fait. Ça m’apprendra (p. 265).

TM1) Un caballero me ha seguido. He tenido la desdichada idea de burlarme, sacando frente a él la punta de mi lengua. "Ah, démela usted», me ha dicho incontinenti. Hay que andarse con tiento (p. 76).

TM2) Un caballero me siguió el otro día y tuve la malhadada idea de sacarle la $\emptyset$ lengua. «¡Oh, démela!» dijo. Esto me enseñará (p. 285).

La omisión en el TM2 de la secuencia léxica "punta de» transforma en español una acción provocativa en una pequeña gamberrada («sacar la punta de la lengua» frente a "sacar la lengua»). Ambas expresiones dibujan dos Claudines diferentes: una, más procaz y atrevida; y la otra, más traviesa y maleducada.

\section{Variante 3}

Vemos aquí el final de un texto epistolar que Charlie escribe a su amigo y compañero de colegio Marcel, primo de Claudine. Se trata de una carta en la que Charlie declara su amor por Marcel.

TO) À toi, corps et âme, Marcelinette. Ton Charlie (p. 301).

TM1) Para mi Marcelita el cuerpo y el alma. Tu Carlos (p. 134).

TM2) Ø Tuyo en cuerpo y alma. Ø Charlie (p. 322).

Como vemos, nuevamente existe un comportamiento distinto de los dos traductores. Uno refleja sin problemas el componente homosexual de la relación que se trasluce en las palabras de la despedida. Mientras, Piñas utiliza la omisión para atenuarlo. En efecto, en el TM1 Charlie se dirige a su amante llamándolo «Marcelita». La feminización del nombre muestra inequívocamente el tipo de relación de que se trata. Además, la despedida se lleva a cabo con la fórmula «Tu Carlos», con un posesivo ausente de la variante consignada en el TM2, en la que ha desaparecido, además, la referencia a «Marcelita» $\mathrm{y}$ en la que se escoge para terminar la carta una fórmula estereotipada que, en consecuencia, puede extenderse a contextos de uso en los que los interlocutores expresan amistad y no una relación más íntima.

\section{Variante 4}

Claudine consigue que Marcel le enseñe una carta de Charlie que constituye una alabanza del amor homosexual y en la que se recurre a referencias literarias que han ensalzado este tipo de relaciones.

TO) Que de bouquins on a fabriqués, déjà, traitant plus ou moins maladroitement de cette question attirante et complexe entre toutes!... Et 
j'ai lu tous ces livres, c'est pourquoi ma chair est triste, hélas ! sauf quand ton souvenir aguicheur la vient ensoleiller (p. 301-302).

TM1) ¡Cuántos libracos se han escrito ya, tratando mejor o peor esta cuestión atractiva y complicada! Si he leído todos esos libros, es porque mi carne está triste, ay, salvo cuando tu recuerdo viene a aguijonearla y encenderla (p. 135).

TM2) ¡Cuántos mamotretos se han elaborado ya, tratando más o menos torpemente de esta cuestión, entre todas atractiva y compleja $\emptyset$ (p. 322).

El TM2 omite una frase completa en la que Charlie explicita claramente su deseo sexual por Marcel.

\section{Variante 5}

Claudine hace comentarios a su primo Marcel a propósito de la carta de Charlie.

TO) C'est fini. Qu'est-ce que je dois dire ? Je suis un peu intimidée par ces histoires de garçons, de gobettes en culottes qui se bichent, comme disait Luce. Ça ne m’étonne pas du tout que le père de Marcelinette ait tiqué, lui aussi... Oh ! je sais bien, je sais très bien que mon neveu est tout à fait ragoûtant, et même pis. Mais l'autre ? Marcel l'embrasse, il l'embrasse ce Charlie phraseur et plagiaire, malgré la petite moustache noire ? Et puis leurs cols de chemise doivent les gêner, parce que, quand on s'embrasse comme ca, il faut nécessairement que l'un des deux ait la tête renversée. J'entends la grande Anaïs me répondre: «Nigaude, bien sûr que non que leurs cols de chemise ne peuvent pas les gêner». Mais Anaïs est une horreur. Marcel ne doit pas être vilain, quand on l'embrasse. Je le regarde en dessous avant de rendre la lettre (p. 303).

TM1) Se acabó. ¿Qué debo decir? Estoy un poco cortada por estas historias de muchachos, de muńecos con pantalones que se requiebran de este modo. No me puede extrañar que el padre de "Marcelita» haya pegado un bote... ¡Ah! Yo sé, yo sé muy bien que mi sobrino es muy apetitoso, y aun más. Pero ¡el otro? Marcelo le besa... besa a ese Carlos pedante y plagiario, a pesar de su bigotillo negro. Además los cuellos de la camisa deben estorbarles porque cuando se besa bien es necesario que uno de los dos tenga la cabeza caída. Ya oigo a la gigantesca Inés contestar. Boba, ten la seguridad de que los cuellos de las camisas no estorban... pero Inés es un horror. Marcelo no debe ponerse feo cuando se le bese. Le miro con desdén antes de devolverle la carta (p. 137).

TM2) ¡Se acabó! ¿Qué debo decir? Me siento un poco intimidada ante estas historias de muchachos. $\varnothing$ No me sorprende en absoluto que el padre de Marcel también brincara. ¡Oh! Sé de sobra que mi «sobrino» es ciertamente "apetitoso», y algo más. Pero y ¿el otro? ¿Besa Marcel a ese Charlie verborreico y plagiario, a pesar del bigotillo negro? $\emptyset$ Marcel no debe de ponerse feo cuando se le besa. Le miro a hurtadillas, antes de devolverle la carta (p. 323). 
ElTM2 soslaya la descripción de los jóvenes como «muñecos con pantalones» y omite una secuencia que explicita de forma gráfica la postura que deberían adoptar los muchachos en el momento del beso.

\section{Variante 6}

Marcel describe a Claudine las experiencias amorosas de Charlie.

TO) En revanche, je comprends à merveille que Charlie, écœuré à la fin des Jules trop complaisantes - tout de même, cette photographie invraisemblable! - ait trouvé adorable la nouveauté d'un enfant qui lui apportait une sentimentalité inédite, avec des scrupules délicieux à vaincre [...] Bouac! ces garçons sont des cochons! Pis: je trouve stupide ce besoin simultané de mépriser et de parodier la femme. Oh! je prévois l'objection: «S’il s'agissait de Luce et d'une autre, que penserais-tu, Claudine?» Elle est idiote, l'objection! D'abord, parce que, ce que je pense, ça ne vous regarde pas; ensuite, des petites filles c'est plus joli. -Décidément, ce Charlie me répugne (p. 306).

TM1) En cambio hallo muy explicable que Carlos, harto por fin de Julio, muy complaciente como demuestra esta fotografía inverosímil, haya encontrado adorable la novedad de un niño en quien saboreaba un

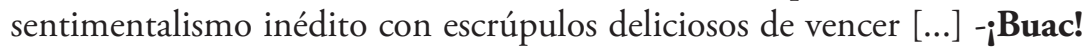
¡Esos jóvenes son muy cochinos! Lo peor de lo peor; encuentro estúpido ese afán simultáneo de despreciar y de parodiar a la mujer. ¡Oh! Preveo la objeción: «Si se tratara de Lucía y de otra, ¿qué pensarías tú, Claudina? » La objeción es estúpida. Ante todo porque pienso lo que a usted no le importa; y además porque entre muchachas es más bonito. Decididamente este Carlos me repugna (p. 142).

TM2) En cambio, comprendo perfectamente que Charlie, al fin asqueado de los Jules demasiado complacientes - -hay que ver esa fotografía inverosímil!-, encontrara adorable la novedad de un niño que le ofrecía una inédita sentimentalidad, con escrúpulos deliciosos de vencer $\emptyset$. Decididamente, este Charlie me repugna (p. 326).

La secuencia omitida en el TM2 desdibuja la naturaleza de los comentarios de Marcel acerca de la homosexualidad masculina y femenina.

\section{Variante 7}

Charlie no ha acudido a la cita convenida con su amante Marcel, y este se lo reprocha en una carta. En otra carta posterior se le insinúa para obligarlo a concertar una nueva cita.

TO) Une pincée de petits bleus, écriture longue et prétentieuse, orthographe hâtive: des rendez-vous fixés ou remis. Des tendresses: «Méchant Charlie! je vous ai attendu rue Lamennais plus d'une heure. Vous serez puni. La 
chère petite place sous l'oreille, je vous l'interdit (sic) trois jours durant... si $j$ 'en ai le courage». Autre billet: «Viens ce soir, j'essayerai pour toi une robe étourdissante, chantilly et paillètes $(s i c)$, dans laquelle je suis à mourir». Et ces deux télégrammes sont signés... Jules! (p. 305).

TM1) Un picoteo de rengloncitos, escritura amplia y pretenciosa, ortografía... «apresurada»; citas dadas o aceptadas. «Ternezas: ¡Malvado Carlos! Te he estado esperando en la calle de Lammenais más de una hora. Será usted castigado. El sitio aquel junto a la oreja, queda prohibido (sic) durante tres días... si tengo valor». Otra carta: «Ven esta noche; me pondré para ti un traje que da gana de desmayarse, de encaje (sic) con el cual estoy matador». Hay dos telegramas firmados por Julio (p. 140).

TM2) Un montón de petits bleus, escritos con letra larga y presuntuosa, de manera apresurada, son citas fijadas o aplazadas: $\varnothing$ Dos telegramas firmados por... jJules! (p. 325).

En esta ocasión, el TM2 omite una secuencia que describe, inequívocamente, aspectos físicos de la relación homosexual masculina, así como la descripción detallada del atuendo "de chantilly et paillètes» con el que Marcel anuncia seducir a su amigo.

\section{Variante 8}

Luce describe a Claudine los pensamientos que pasan por su cabeza en el momento en que su tío utiliza la fuerza para mantener con ella relaciones sexuales. Para ello, recurre a una analogía literaria.

TO) Et puis, malgré moi, je songeais pendant ce temps-là au viol d'Ossaire!, tu t'en rappelles, ce libraire d'Ossaire, Petitrot, qui avait violé une de ses employées. Nous lisions dans ce temps-là Le Moniteur du Fresnois en cachette et nous retenions des phrases par coeur: «Il la jeta sur le lit et s'étendit sur elle... Elle voulut s'échapper, mais, il la retint... si brutalement qu'elle en poussa des cris de douleur ". Ces souvenirs-là, tout de même, ça reparaît mal à propos (p. 318).

TM1) -Además, a pesar mío, pensaba mientras tanto en la violación de Ossaire, ya te acuerdas, aquel librero de Ossaire, Petitrot, que había violado a una de sus dependientes. Nosotras leíamos el Monitor de Fresnois de ocultis y no olvidábamos algunas frases: «El la arrojó sobre el lecho y se extendió sobre ella... ella quiso escapar, pero él la contuvo... tan brutalmente, que ella lanzó quejidos dolorosos». Estos recuerdos, en el mismo instante, parecían advertirme que esas palabras estaban precisamente escritas para mí (p. 161).

TM2) -Y luego, sin querer, todo el rato pensaba en la violación de Ossaire. ¿Recuerdas al librero de Ossaire, Petitrot, que había violado a una de sus empleadas? En aquel tiempo leíamos a escondidas el Moniteur du Fresnois, y aprendíamos de memoria frases enteras. $\varnothing$ Lo malo es que esos recuerdos vuelvan a veces con muy poca oportunidad (p. 338). 
Nuevamente el TM2 omite una secuencia donde se evoca de forma explícita el acto de la violación. Una frase escueta («había violado a una de sus empleadas») constituye la única referencia a un acto sexual violento que en el TM1 aparece dibujado con todos sus detalles.

\section{Variante 9}

El padre de Claudine se dirige a su hija para hablarle del interés que el señor Maria tiene por casarse con ella.

TO) Ce brave petit monsieur Maria veut t'épouser, même dans un an si tu te trouves trop jeune. Moi, tu comprends, j'oublie un peu ton âge, depuis le temps (!). Je lui ai répondu que tu devais avoir au juste quatorze ans et demi, mais il m'affirme que tu cours sur dix-huit ; il doit le savoir mieux que moi. Voilà ! (p. 345).

TM1) -Este buen señorito, Maria, quiere casarse contigo, aunque sea dentro de un año, si crees que eres muy joven todavía. Yo, como comprendes, olvido algo tu edad desde hace tiempo. Le he contestado que debías tener exactamente catorce ańos y medio, pero él me asegura que has cumplido ya los diecisiete; y debe saberlo mejor que yo (p. 205).

TM2) -Este buen monsieur Maria quiere casarse contigo, aunque sea dentro de un año si te parece que eres demasiado joven. Yo, como comprenderás, con el tiempo me he olvidado de la edad que tienes. Le he contestado que, a lo sumo, tenías catorce años y medio, pero él afirma que tienes cerca de dieciocho! Ø (p. 366).

La omisión de la frase "y debe saberlo mejor que yo» impide que el lector realice inferencias acerca de la posible relación que Claudine haya podido tener con el personaje, puesto que el Sr. Maria, según insinúa el padre, dispone de evidencias sobre la edad de la chica.

\section{Variante 10}

Luce entrega a Claudine, su gran amor, unos objetos que ella misma ha embrujado para que esta no los pierda y así la tenga siempre presente.

TO) (Pour ceux qui ignorent le sortilège d'empicassement, voici: Vous posez à terre l'objet $\mathrm{o}$, à empicasser, vous l'enfermez entre deux parenthèses dont les bouts rejoints $(\mathrm{o}+)$ se croisent et où vous inscrivez, à gauche de l'objet, une croix. Après ça, vous pouvez être tranquille, l'empicassement est infaillible. On peut aussi cracher sur l'objet, mais ce n'est pas absolument indispensable) (p. 226).

TM1) (Para los que ignoran cómo se asegura un objeto embrujándolo, ahí va la receta: se pone sobre la tierra, se hace a su izquierda una cruz y se cierra todo en un paréntesis, cuyos extremos, cortándose arriba y abajo, forman otras dos cruces: se puede también escupir encima para mayor seguridad, pero no es indispensable: queda formalizado el embrujamiento sin este requisito.) (p. 12). 
TM2) (Para los que ignoren el sortilegio pertinente), helo: se pone en el suelo el objeto que se desee encantar, se le encierra entre dos paréntesis, cuyos extremos deben cruzarse, $\mathbf{y}$ se escribe una $\mathbf{X}$ a la izquierda del objeto. Una vez hecho esto, quédense tranquilos, el encantamiento es infalible. Se puede, también, escupir sobre el objeto en cuestión, pero no es absolutamente indispensable (p. 246).

Vemos cómo el TM2 considera irreverente ante la moral católica la mención de la cruz en un contexto de brujería y sustituye esta palabra por el signo X.

\section{Variante 11}

Al final de la novela, Juliana, la criada de Claudine, se dirige a la joven en el momento en el que esta, recién casada, entra en su habitación en brazos de su marido, su tío Renaud, padre de Marcel, al que besa ante la pesadumbre del señor Maria.

TO) Et nous retournons dans ma chambre, moi toute serrée dans son bras, lui qui m'emporte comme s'il me volait, tous deux ailés et bêtes comme des amoureux de romance. Vite, allons-nous-en, pour que je ne voie plus le dos triste de M. Maria qui n’a pas tourné une fois la tête pendant ce dialogue de vaudeville, qui n'a pas ri, qui gratte, assidu, une tache humide sur son papier. Une tache, pauvre homme!... Et comme nous nous sommes arrêtés, silencieux, contre la porte fermée où il $\mathrm{m}^{\prime}$ embrasse, encore, encore, encore..., cette porte s'ouvre rudement devant Mélie, porteuse du plat de sciure où s'épanchera Fanchette. Non, la figure de Renaud! Mélie a disparu après un philosophique: «A votre bonne santé». Mais je me précipite derrière elle: «Mélie, Mélie, écoute !» C’est celui-là, c'est celui-là ! Je serai sa femme, j'aurai ce grand mari-là pour moi toute seule !-Pour toi toute seule, ma petite servante ? Je te connais, réaude, $\mathrm{y}$ en aura pas guère de trop. Et puis t'as bien raison de prendre le grand. -N'est-ce pas ? -Pardi, il sera toujours bien temps, si la marchandise te plaît point, de t'appliquer le petit! (p. 376).

TM1) Y volvemos a mi cuarto, yo oprimida por entero por sus grandes brazos; él, arrebatándome como si me robase; los dos, alados y tontos como dos enamorados de novela. Aprisa, vamos pronto, para que no vea yo la espalda triste del seńor Maria, que no ha vuelto una vez la cabeza durante este diálogo de comedia, que no ha reído, que raspa, con esmero, una mancha húmeda caída en el papel en que escribe. ¡Una mancha, pobre hombre! Y como nos hemos detenido silenciosos, apoyados en la puerta cerrada donde él me besa aún, aún, aún... la puerta se abre con violencia ante Juliana, portadora de un plato de serrín, donde Mariposa hará lo que necesite. ¡Qué cara la de Renaud!... Juliana ha desaparecido después de un filosófico: -iQue aproveche! Pero yo me precipito detrás de ella: -Juliana, Juliana, óyeme. ¡Es este, es este! ¡Seré su mujer y tendré todo ese gran marido para mí solita! 
- ¿Para ti sola, chiquita mía? Te conozco, monuela y no tendrás de más. Además, has hecho muy bien en tomar al grande. - ¿Verdad que sí? - ¡Caramba! Siempre habrá tiempo, si la mercancía te agrada poco, de aplicarte al pequeño (p. 258).

TM2) Y volvemos a mi cuarto, yo acurrucada en sus brazos, él llevándome como si me raptara, ambos alados y tontos como dos enamorados de leyenda $\varnothing$ (p. 397).

Esta variante es fundamental para comprobar la intención del TM2, puesto que se trata de la que pone fin al relato. Como vemos, el TM2 cierra la narración con una escena en la que la audaz y traviesa Claudine es redimida por medio del amor al contraer matrimonio con el maduro Renaud. El texto hace hincapié en la idea de que Claudine se casa enamorada («ambos alados y tontos como dos enamorados de leyenda»). Esta función del matrimonio, sacramento que consagra mutuamente a los contrayentes, concede a la protagonista el perdón del pecado de sus andanzas juveniles y cierra su pasado introduciéndola en una nueva vida de mujer casada, acorde con los preceptos de la moral católica.

Evidentemente, este final constituye una manipulación de la obra original, en la que el matrimonio queda configurado como una etapa más de la evolución de Claudine, tal y como se infiere de las palabras de la criada traducidas fielmente por el TM1 («¿Para ti sola, chiquita mía? Te conozco, monuela y no tendrás de más. Además, has hecho muy bien en tomar al grande. ¿Verdad que sí? ¡Caramba! Siempre habrá tiempo, si la mercancía te agrada poco, de aplicarte al pequeño»). Podemos observar la visión materialista que se desprende de estas palabras: el marido es una "mercancía» valorada por el tamaño (Claudine se hace con la experiencia de un hombre mayor), y el matrimonio no constituye una puerta cerrada, pues la infidelidad siempre será posible («siempre habrá tiempo de aplicarte al pequeño»). Toda esta información desaparece del TM2.

De este modo, el TM1 dibuja un personaje que, aunque joven, tiene plena conciencia de sus acciones. El TM2, por el contrario, configura una Claudine traviesa, que no tiene verdadera conciencia del alcance de sus actos, que pueden considerarse simples chiquilladas propias de la edad y que, a pesar de forzar los límites de lo permitido, pueden perdonarse. En el texto de Piñas está claro que la chica recobra el buen juicio al decidirse a contraer matrimonio, y sus andanzas, que quedan en el pasado, no dejan de ser consecuencia del deseo de experimentación inherente a la etapa de la adolescencia.

\section{Conclusiones}

El análisis desarrollado nos ha permitido confirmar las hipótesis que nos sirvieron de punto de partida. En este sentido, hemos comprobado que el traductor del TM2 dedica especial atención a los aspectos relacionados con la moral sexual, especialmente los que tienen que ver con la homosexualidad, y manipula el texto con el fin de suavizar aquellas situaciones que sobrepasan los límites socialmente aceptados por el pudor y las buenas costumbres. 
Del mismo modo, dedica sus esfuerzos a atemperar los segmentos textuales que presentan un lenguaje que en la sociedad espańola de la época puede ser considerado provocativo o indecoroso y de aspectos que afectan a la religión y que pueden resultar ofensivos o irreverentes, de acuerdo con los presupuestos morales católicos. La obra estudiada no posee intencionalidad política, por lo que no hemos encontrado variantes referidas a este ámbito.

Por otra parte, el análisis de variantes corrobora el principio de que la traducción es un proceso de reescritura, mediante el cual el traductor reelabora la obra para adaptarla a las expectativas de la sociedad receptora. De igual modo nos ha permitido comprobar que la traducción de 1963 matiza la configuración del mundo novelado aplicando, especialmente, la técnica de la omisión pero recurriendo, igualmente, a la transformación de las secuencias mediante procedimientos léxico-semánticos.

Frente a la versión de 1910, que presenta al personaje de Claudine como una joven que sale de la niñez y vive su sexualidad en libertad y con plena conciencia de sus actos, la versión de 1963 configura la trayectoria vital de la Claudine adolescente como una etapa de descubrimientos y equivocaciones que pueden achacarse a la inmadurez y el atolondramiento propios de la edad, por lo que su conciencia ante sus actos queda atenuada. Esta etapa se cierra al final de esta versión con el "candado» del matrimonio, concebido como sacramento religioso que redimirá a la joven de las experiencias de juventud.

$\mathrm{El}$ análisis de variantes ha puesto de relieve, igualmente, que las diferencias señaladas no afectan solamente al diseño del carácter de la protagonista, Claudine, sino que inciden también sobre el perfil de los otros personajes, los jóvenes amigos de Claudine, y de su primo Marcel. Relaciones homosexuales o bisexuales quedan claramente dibujadas en la traducción de 1910 y sugeridas o desdibujadas en la versión de 1963. Al igual que sucede con Claudine, los jóvenes del TM1 saben lo que hacen y lo que quieren, tienen plena conciencia de sus actos y buscan la experimentación y el conocimiento, además del placer. Por el contrario, la conciencia de los jóvenes que perfila el TM2 queda más desdibujada: lo que el traductor más antiguo diseña como escenas picantes, el traductor de 1963 lo convierte en travesuras.

En definitiva, como afirma Toury (1985), la preocupación del traductor no es tanto llevar a cabo un trabajo acorde con las normas del original como adecuarse a las normas que rigen el sistema cultural receptor. Así, se comprueba cómo se desdibuja el carácter sagrado del original, y cómo las desviaciones de este original devienen de los condicionamientos del sistema literario meta.

\section{Bibliografía}

Abella R., La vida cotidiana en España bajo el régimen de Franco, Barcelona, Argos Vergara, 1985.

Abellán M., Censura y creación literaria en España (1939-1976), Barcelona, Ediciones Península, 1980. 
Amorós A., Introducción a la literatura, Madrid, Castalia, 1987.

Beneyto A., Censura y política en los escritos españoles, Barcelona, Euros, 1975.

Colette S. G., Claudine à Paris, en Colette. CEuvres, Bibliothèque de la Pléiade, Paris, Gallimard, 1901, pp. 216-377.

Colette S. G., Claudine en París, L. Ruiz Contreras trad., Madrid, Francisco Beltrán, 1910 .

Colette S. G., Claudine en París, E. Piñas trad., Barcelona, Plaza y Janés, 1963.

Cobos Castro E., "Narrativa y traducción: la novela popular francesa traducida al español en la $2^{\mathrm{a}}$ mitad del siglo XX», en Estudios de investigación franco-española 12, 1995, pp. 185-216.

Díaz Peralta M., Piñero Piñero G. y García Domínguez M. J., «Ideología y selección lingüística en los textos históricos: las traducciones españolas de History of the conquest of Mexico de W. H. Prescott», Babel 54:3, 2008, pp. 251-267

Díaz Peralta M., Piñero Piñero G. y García Domínguez M. J., "Adaptation Strategies in historical texts: The Spanish version of History of the Reign of Philip the Second, King of Spain by William H. Prescott», Intercultural Pragmatics 10:3, 2013, pp. 495520 .

Díaz-Peralta M., Pinero-Pinero G., García-Domínguez M. J. y Boylan G., «Metaphor and symbol: The portrait of Montezuma II in the work of W. H. Prescott and its translation in to Spanish by J. Navarro", Babel 61:2, 2015, pp. 242-264.

Delisle J., L'analyse du discours comme méthode de traduction. Initiation à la traduction française de textes pragmatiques anglais: théorie et pratique, Ottawa, Èditions de l'Université d'Ottawa, 1980.

Gallego Roca M., «De las vanguardias a la guerra civil. Notas para un capítulo de la historia de la traducción literaria en España a principios del siglo XX», en Historia de la traducción en España. F. Lafarga y L. Pegenaute eds., Salamanca, Ambos Mundos, 2004, pp. 479-526.

Gómez Castro C., «Traduzione Tradizione? El polisistema literario español durante la dictadura franquista: la censura», en Revue des Littératures de L'Union Européenne 4, 2006, pp. 37-39.

Hermans T., «Introduction: Translation Studies and a new Paradigm», en The Manipulation of Literature. Studies in Literary Translation, T. Hermans ed., Londres y Sidney, Croom Helm, 1985, pp. 7-15.

Holmes J., Translated. Papers on Literary Translation and Translation Studies, Amsterdam, Rodopi, 1988.

Laín Entralgo P., Descargo de conciencia, Barcelona, Barral, 1976.

Lefevere A., Traducción, reescritura y la manipulación del canon literario, C. A. Vidal y R. Álvarez trads., Salamanca, Ediciones Colegio de España, 1997.

Moya V., La selva de la traducción, Madrid, Cátedra, 2004.

Pegenaute L., "La época realista y el fin de siglo», en Historia de la traducción en España, F. Lafarga y L. Pegenaute eds., Salamanca, Ambos Mundos, 2004, pp. 397478.

Rabadán R., "Tendencias teóricas en los estudios contemporáneos de traducción», en Estudios de traducción, P. Fernández Nistal ed., Valladolid, Universidad de Valladolid, 1992, pp. 45-50. 
Reiss K y H. J. Vermeer, Fundamentos para una teoría funcional de la traducción, H. Witte y C. Martín trads., Madrid, Akal, 1996.

Ruiz Casanova F., Aproximación a una historia de la traducción en España, Madrid, Cátedra, 2000.

Santoyo J. C., La cultura traducida. Lección inaugural del curso académico 1983-84, León, Universidad de León, 1983.

Serrano Súner R., Entre Hendaya y Gibraltar, Madrid, Ediciones y publicaciones españolas, 1947.

Sinova J., La censura de prensa durante el franquismo, Madrid, Espasa- Calpe, 1989.

Suárez Fernández L., Francisco Franco y su tiempo, Madrid, Fundación Nacional Francisco Franco, 1984.

Toury G., "A Rationale for Descriptive Translation Studies», en The Manipulation of Literature: Studies in Literary Translation, Londres y Sydney, Croom Helm, 1985, pp. 184-187.

Vega M. Á, «De la Guerra Civil al pasado inmediato», en Historia de la traducción en España, F. Lafarga y L. Pegenaute eds., Salamanca, Ambos Mundos, 2004, pp. 527578 . 
